\title{
Bioinformation
}

\section{Comparative sequence analysis of acid sensitive/resistance proteins in Escherichia coli and Shigella flexneri}

\author{
Selvaraj Manikandan ${ }^{1, \$}$, Seetharaaman Balaji ${ }^{2, \$}$, Anil Kumar ${ }^{1}$ and Rita Kumar $^{1, *}$ \\ ${ }^{1}$ Institute of Genomics and Integrative Biology, Mall Road, Delhi - 110007, India; ${ }^{2}$ Department of Biotechnology, Manipal Institute \\ of Technology, Manipal University, Manipal - 576104, India; ${ }^{\$}$ Both the authors contributed equally \\ Rita Kumar* - E-mail: rita@igib.res.in; Phone: 9111 27662133; Fax: 9111 276674711; Corresponding author
}

received September 17, 2007; revised October 25, 2007; accepted November 22, 2007; published online December 11, 2007

\begin{abstract}
:
The molecular basis for the survival of bacteria under extreme conditions in which growth is inhibited is a question of great current interest. A preliminary study was carried out to determine residue pattern conservation among the antiporters of enteric bacteria, responsible for extreme acid sensitivity especially in Escherichia coli and Shigella flexneri. Here we found the molecular evidence that proved the relationship between E.coli and S.flexneri. Multiple sequence alignment of the gadC coded acid sensitive antiporter showed many conserved residue patterns at regular intervals at the $\mathrm{N}$-terminal region. It was observed that as the alignment approaches towards the C-terminal, the number of conserved residues decreases, indicating that the Nterminal region of this protein has much active role when compared to the carboxyl terminal. The motif, FHLVFFLLLGG, is well conserved within the entire gadC coded protein at the amino terminal. The motif is also partially conserved among other antiporters (which are not coded by gadC) but involved in acid sensitive/resistance mechanism. Phylogenetic cluster analysis proves the relationship of Escherichia coli and Shigella flexneri. The gadC coded proteins are converged as a clade and diverged from other antiporters belongs to the amino acid-polyamine-organocation (APC) superfamily.
\end{abstract}

Keywords: amino acid -polyamine-organocation (APC); Glutamate decarboxylase (GadC); bacteria; sequence; proteins

\section{Background:}

Microbes are not always boned to have the favorable condition for their survival. So as to tackle the unfavorable conditions, they adopt certain mechanisms to overcome it. All enteric pathogens are required to bypass the acidic environment of stomach before infecting the intestinal mucosa, where luminal $\mathrm{pH}$ approaches neutrality. [1] Enteric micro-organisms have developed several inducible mechanisms for surviving transient periods of extreme acid stress. [2] Though such acid resistance mechanism is found in Enterobacteriaceae family but it is not the characteristic feature of all microbes of the family. Escherichia coli and Shigella flexneri have been reported to possess the acid resistance mechanism [3] where gadA and gadB genes code for the isoforms of glutamate decarboxylase (GAD). The gad system is based on the coordinated action of these two homologues of glutamate decarboxylase and of a specific glutamate/gamma-aminobutyrate antiporter (GadC) [4], in which glutamate is internalized and converted to $\gamma$ aminobutyrate (consuming an intracellular proton) that is subsequently exchanged for another extracellular glutamate via a membrane-located antiporter. [5] Gale and Epps [6] as well as others $[7,8]$ demonstrated that there are a variety of decarboxylases that respond to low $\mathrm{pH}$. The putative glutamate/GABA antiporter which is encoded by the gadC gene is responsible for importing the glutamate inside the cell

ISSN 0973-2063

Bioinformation 2(4): 145-152 (2007) and simultaneously exporting the GABA to the acidic environment. This helps for neutralization and survival in the acidic environment. The acid sensitivity inner membrane antiporter protein plays a pivotal role in the acid resistance indirectly, it is also found that mutation in the inner membrane antiporter protein makes the organism acid sensitive as neither intake of glutamate nor export of GABA takes place, which pave an acidic environment where the microbes will undergo death phase. This specific GABA antiporter belongs to the amino acid -polyamineorganocation (APC) super family. Gad A, B, C, hde AB, all are essential for the expression of acid resistance strains and mutations in any of these regions may block gludependent systems. [9] These genes encode a glutamatedependent acid resistance mechanism that is optimally active under conditions in which it is needed to maintain viability. [10]

Present study deals with gadC encoded inner membrane antiporter due to its importance in transporting glutamate across inner membrane through gadC and making favourable environment for surviving in extreme condition. [9] Here we tried to decipher, is there any evidence hidden in the antiporter protein, of Escherichia coli K-12, O157:H7 and Shigella flexneri? Because this mechanism 


\section{Bioinformation}

\section{www.bioinformation.net}

was not found in any other Enterobacteriaceae. We suspect that there must be some sequence conservation which was not detected in other enterobacteriaceae. GadC of Listeria monocytogenes has a motif FHLVFFLLLGG that corresponds to the Shigella flexneri GadC FSLVFFLLLGG and is considered to play an important role in the recognition of the glutamate. [5] Here we also address this pattern in the rest of the gadC coded acid sensitive/resistance proteins and other antiporters of APC super family as well.

\section{Methodology:}

The key word 'gamma aminobutyrate antiporter' yielded 290 hits of protein sequences from GenBank [URL http://www.ncbi.nlm.nih.gov/Genbank/]; Synonyms to gadCXasA coded antiporter proteins were also retrieved. [11] From the 290 hits, gadC coding proteins were selectively chosen; besides, a few amino acid antiporters and arginine/ornithine antiporters were also included for analysis (Table 1 under supplementary material). The other antiporters such as, putrescine-ornithine antiporters, lysine:cadaverine antiporters, histidine/histamine antiporters were omitted from our analysis data.

A multiple sequence alignment was done by using Clustal $\mathrm{X}$ Ver.1.83 [12], the gap opening was set at 10.00, the gap extension at 0.20 with $30 \%$ delay divergent sequences and Gonnet series weight matrix was used. From the multiple sequence alignment, the guide tree was derived. To justify the confidence of the clades, re-sampling method (bootstrap) was used with 10000 trails. Web logo (ver 2.8.2) was used to identify the conserved pattern in the gadC coded antiporters of Enterobacteriaceae. Alignments were analysed and phylogenetic relationships among the sequences were established using different procedures: Neighbour-Joining (NJ) [13], Fast Minimum Evolution (FastME) [14] Unweighted Pair Group Method with Arithmetic Mean (UPGMA). [15] The final tree was displayed by using MEGA 3.1 [16], the nodes and clades of gadC antiporters were traced out by visual examination.

\section{Results and discussion:}

\section{Tracing the gadC cluster among the antiporters}

A preliminary multiple sequence alignment was carried out among all antiporters of enteric bacteria belonging to the APC superfamily. Based on the multiple sequence alignment and tree construction with 10000 bootstrap trials Figure 1 shows that the gadC coded proteins form a separate cluster from other antiporters which belong to APC super family.

The similar trend was also observed in phylogenies obtained by using different methods (NJ, UPGMA and FastME). The antiporter sequence of Rhodopirellula baltica (NP_864077) which belongs to proteobacter was used as an out-group. The convergence of gadC coded antiporters stands separately from other antiporters which comprises of Listeria monocytogenes, Clostridium perfringens, Lactococcus lactis E. coli, S. flexneri and $S$. dysenteriae.

ISSN 0973-2063

Bioinformation 2(4): 145-152 (2007)

\section{Evolutionary distance between antiporters}

From Figure 2, it is clear that ten major proteins coded by gadC forms the root of the tree $(0.0)$ which corresponds to the gadC cluster (shown in Figure 1). The out group used showed maximum deviation (0.90) and $100 \%$ confident divergence from other antiporters from other operational taxonomical units (OTUs). The root comprises antiporters from $S$. flexeneri M25-8A, S. flexeneri, E.coli 06, E. coli UT189, E. coli CFT073, E. coli K-12, E. coli K-12: W3110 and E. coli 0157:H7. This proves the very close relationship of E. coli and S. flexneri. Whereas the S. dysenteriae Serovar 1 was little diverged (0.01) form the root and shows the close relationship with the root.

A slightly deviated cluster from the root $(0.43-0.47)$ which corresponds to the gadC cluster shown in Figure 1 comprises of Listeria monocytogenes EGD5, L. monocytogenes LO28 (0.44), Clostridium perfringens str.13 (0.43), Lactococcus lactis subsp. Cremoris, L. lactis subsp. cremoris MG1363, L. lactis subsp. Lactis str. IL1403 (0.47) shows a close relationship among each other. This is congruent with Sanders et al (1998), showed that Lactococcus lactis gadC is homologous to putative glutamate-gamma-aminobutyrate antiporters of $E$. coli and $S$.flexneri [10] and also with Cotter et al (2001), showed that L. monocytogenes GadC shares high homology, $65 \%$ and $51 \%$ identity (77\% and $68 \%$ similarity) with the equivalent transporters in the L. lactis and E. coli. [5]

The root (0.0) and the closely related cluster (0.43-0.47) have the conserved LVFFLLLGCC motif. The conservation goes on decreases with respect to other clusters or distantly related antiporters and reveals that electrochemical-potential-driven transporters essential for the expression of acid resistance, could not be detected in other family members of the Enterobacteriaceae. [17]

In contrast to neutralophilic bacteria such as Salmonella typhimurium, E. coli and Shigella have acid resistance systems which are unique. [2] Moreover the acid resistance in E.coli and Shigella species is similarly regulated. [18] Hence our main focus lies on gadC; the gadC clade was analyzed separately so as to determine the relationship between $E$. coli and S. flexneri because studies conducted by Lin et al. [3] showed that the toxic strain of E.coli, H10407 did adapt well at $\mathrm{pH} 4.3$, although not quite as well as $S$. typhimurium UK1. It was also considered possible that two other strains of $E$. coli and $S$. flexneri might respond better to an acid shock at a less acidic $\mathrm{pH}$. Therefore a separate sequence analysis was carried out between $E$. coli strains and S. flexneri. Careful analysis of multiple sequence alignment of E. coli [P63235], E. coli 0157:H7 [P58229], E. coliO6 [Q8FHG6], showed that these organisms have $98-99 \%$ homology with their closely related clades of phylogeny (Figure 3). This high similarity may be due to the two glutamate decarboxylases, encoded by gadA and gadB, with gadB forming part of an operon with the antiporter determinant gadC. These homologues obviously resulted from a gene duplication event, given that they share $98 \%$ and $99 \%$ similarity at the DNA and protein levels respectively [19] as shown in Figure 3. 


\section{www.bioinformation.net}

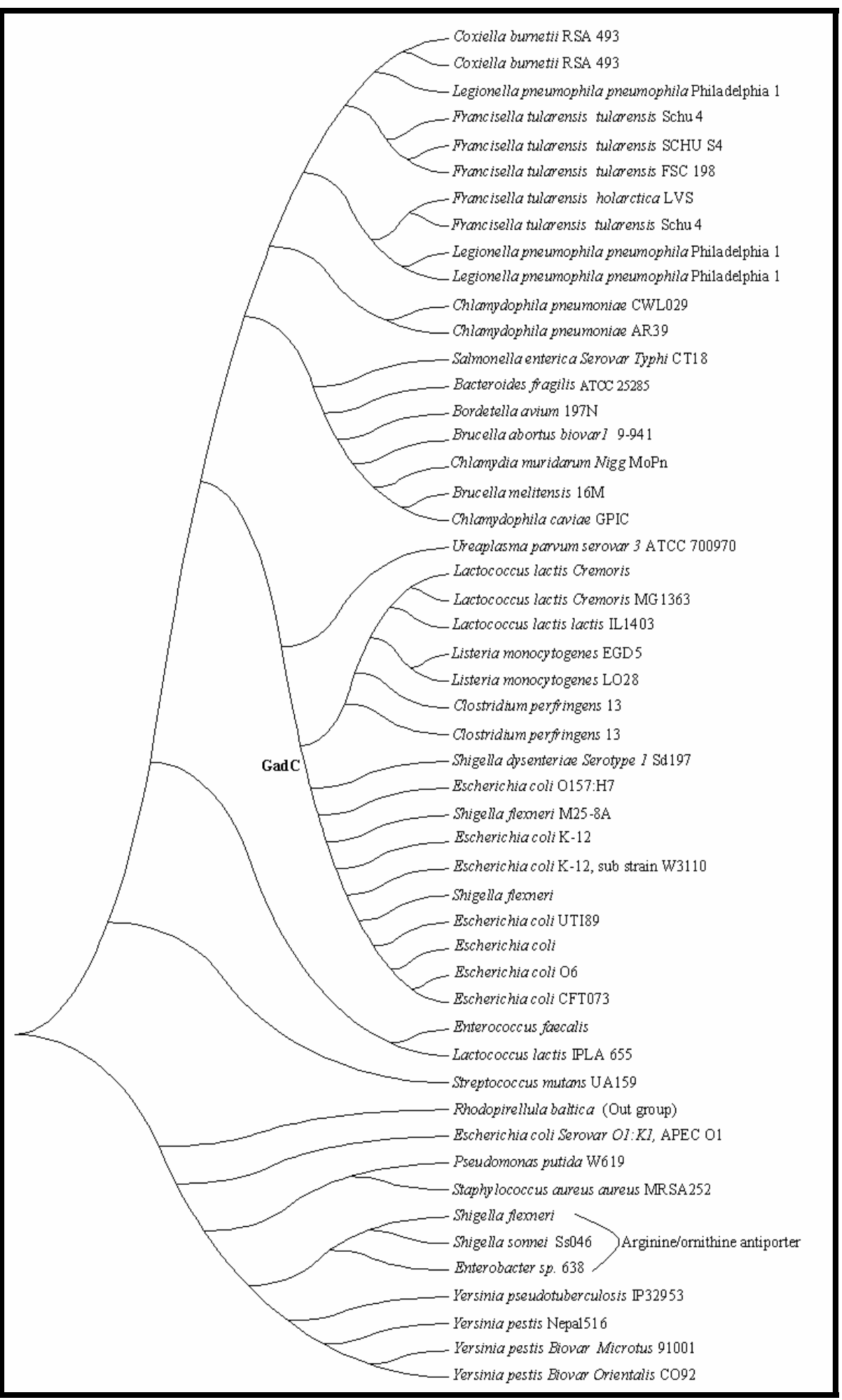

Figure 1: The phylogenetic tree with 10000 bootstrap trials shows a separate cluster of gadC coded proteins among other antiporters belong to amino-acid-polyamine-organocation (APC) superfamily. The similar trend was also observed by using different methods (NJ, UPGMA, and FastME). Each branch shows the organism name followed by sub-species and strain.

ISSN 0973-2063

Bioinformation 2(4): 145-152 (2007)
147

Bioinformation, an open access forum (c) 2007 Biomedical Informatics Publishing Group 


\section{Bioinformation}

\section{www.bioinformation.net}

Hypothesis

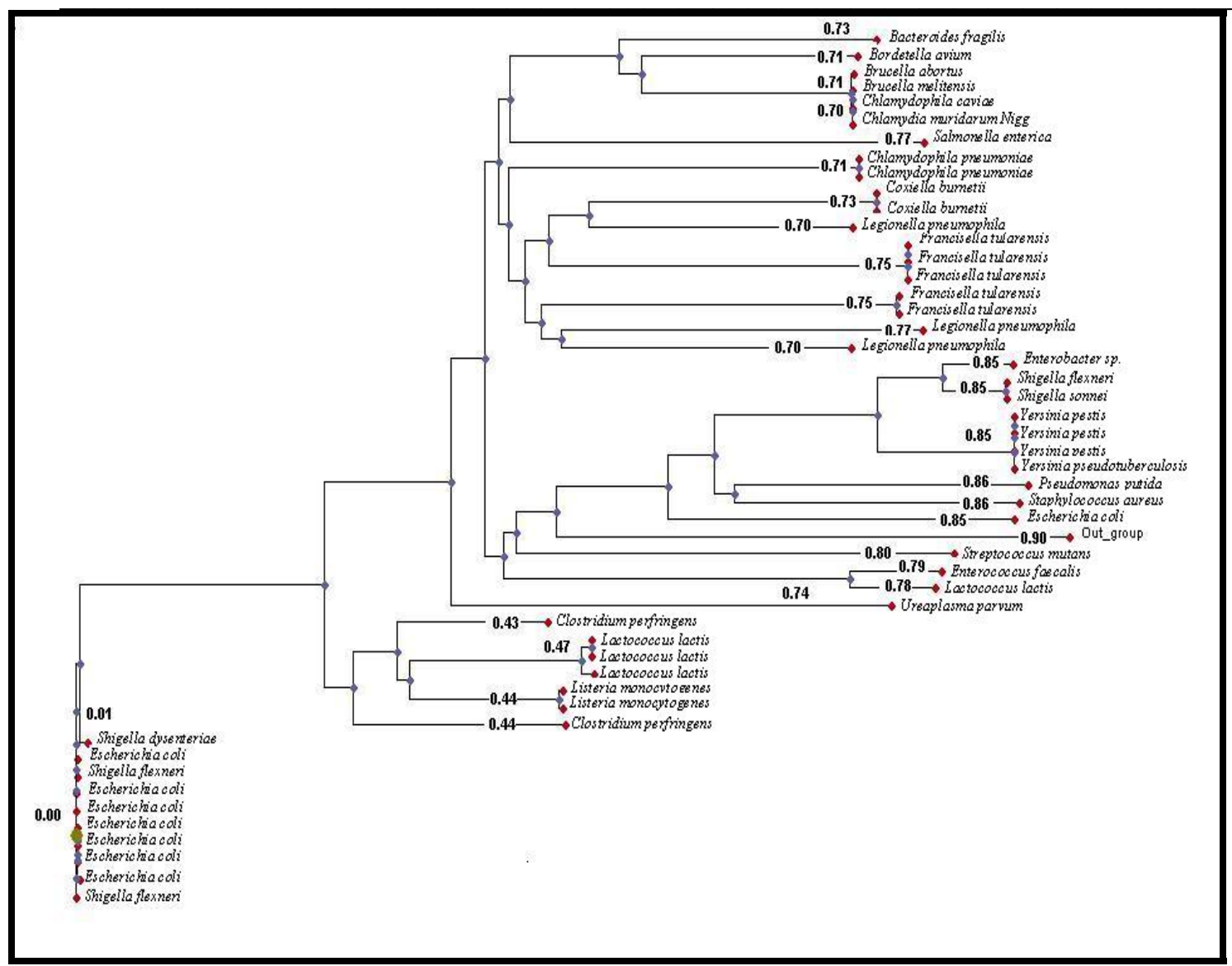

Figure 2: Phylogram shows the branch lengths / evolutionary distances among antiporters.

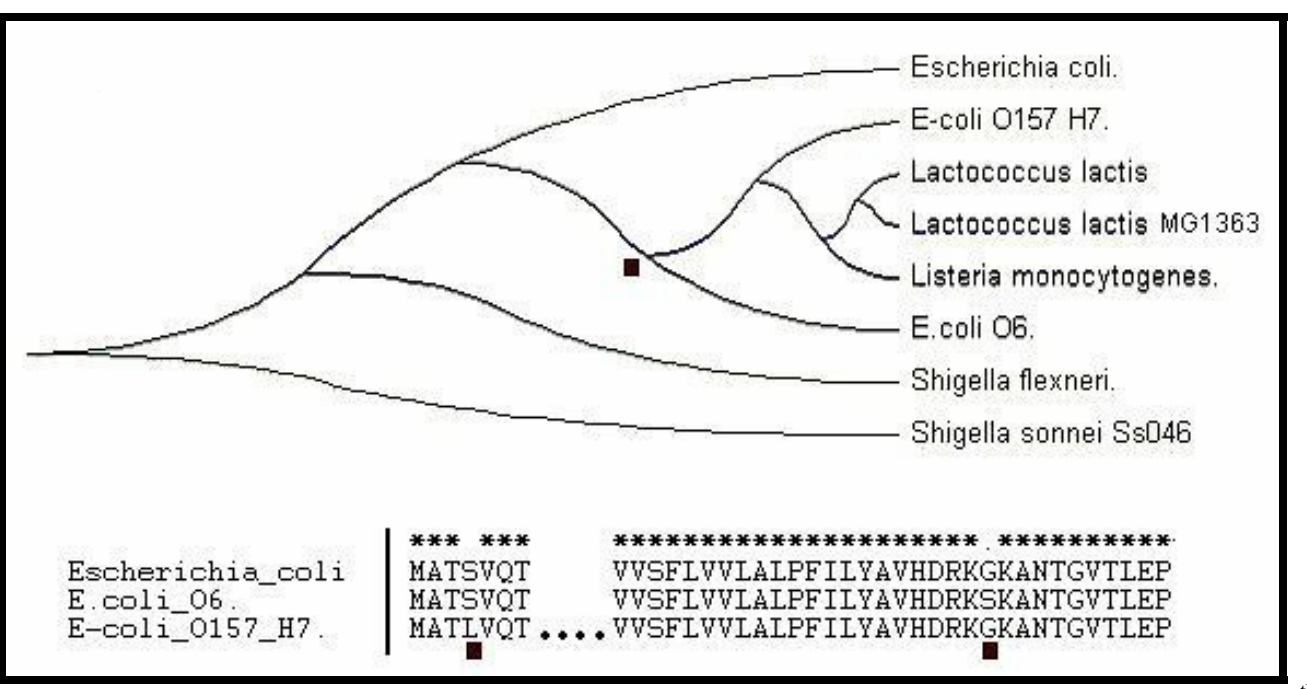

Figure 3: Relationship between the E.coli and its strains with S.flexneri. The dual mutations one at $4{ }^{\text {th }}$ residue and the other at $470^{\text {th }}$ amino acid are represented as blocks. The descendants of E.coli strains such as E.colib0157:H7 and E.coliO6 might have deviated at a particular evolutionary time period because of the dual mutation occurred in the sequence (indicated as blocks). 


\section{www.bioinformation.net}

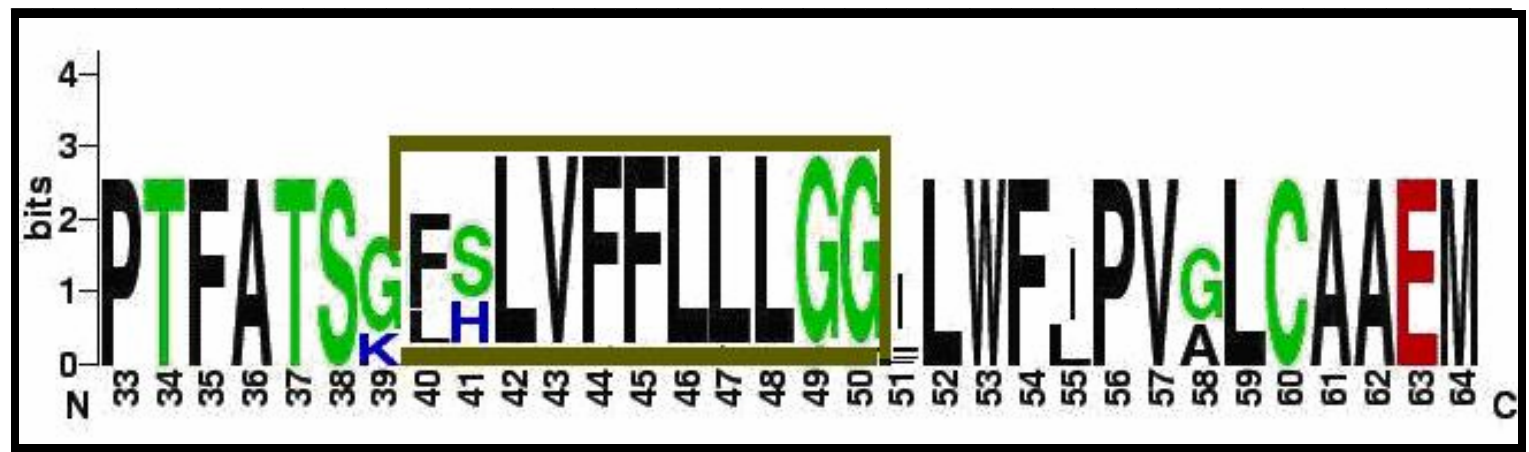

Figure 4: Web logo (ver 2.8.2) was used to identify the consensus region of the N-terminal among the gadC coded proteins which is shown in box.

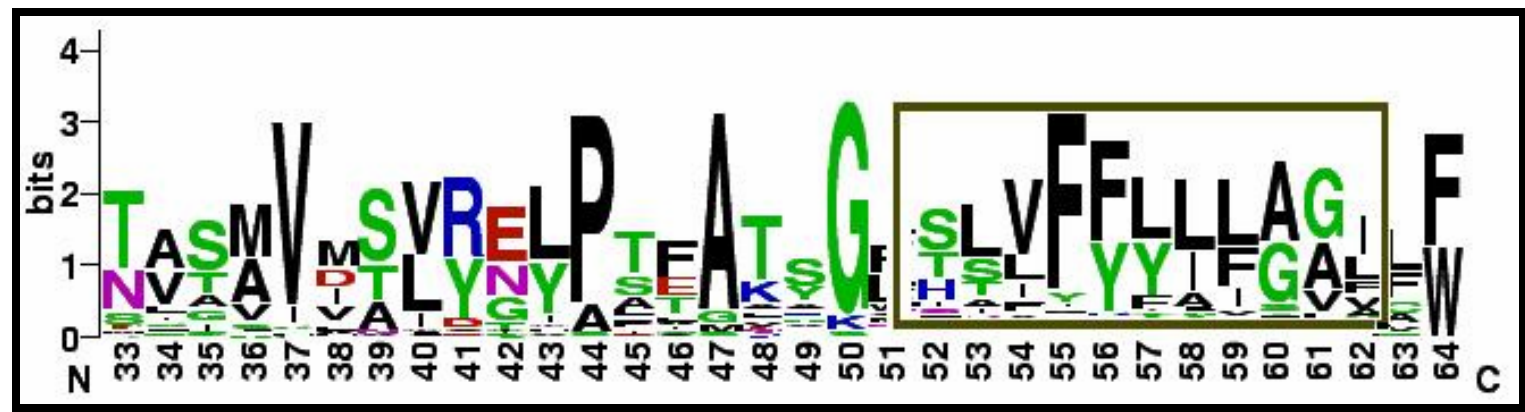

Figure 5: Web logo (ver 2.8.2) was used to identify the consensus region of the N-terminal among the antiporter proteins not coded by gadC which is shown in box.

\begin{abstract}
Distinct pattern conservation of glutamate binding region

Multiple alignment of the gadC coded acid sensitive antiporter showed many conserved residue patterns in a regular interval at the $\mathrm{N}$-terminal region and as the alignment approached the $\mathrm{C}$-terminal end, the number of conserved residues decreased, indicating that the $\mathrm{N}$ terminal region of this protein has a much active role when compared to the carboxyl terminal end. The motif FSLVFFLLLGG is considered to play an important role in the recognition of the glutamate and our alignment analysis (Figure 4) confirmed that the motif FHLVFFLLLGG was well conserved within the entire gadC coded proteins (at the amino terminal). It proved that the FHLVFFLLLGG motif is not only unique for Shigella flexineri but also for the other gadC coded bacteria such as Escherichia coli, E. coli O157:H7, E. coli O6, Shigella sonnei Ss046, Lactococcus lactis subsp. lactis, Lactococcus lactis subsp. cremoris and Listeria monocytogenes.
\end{abstract}

We also extended our analysis to address the pattern conservation among the other antiporters (which are not coded by gadC) involved in acid sensitive/resistance mechanism. Amazingly we found that the pattern is still partially conserved for the acid sensitive/ resistance mechanism (Figure 5). This pattern conservation also depicts that the function is highly dependant on the pattern used for the acid resistance. The motif 'FHLVFFLLLGG' was well conserved with the entire gadC coded proteins at

ISSN 0973-2063

Bioinformation 2(4): 145-152 (2007) the amino terminal where the binding residue could be found with in the first and second transmembrane helices. [5] The partial conservation of this motif among the other antiporters (not coded by gadC) is due to the poor acid resistance. The strong motif conservation could be the reason for the extreme acid resistance of $E$. coli and $S$. flexneri. Our pattern analysis shows the relationship of Escherichia coli and Shigella flexneri. This can be correlated with the claims of Waterman and Small (2003) [19], for a strong-link between the possession of the gadC genes and the expression of stationary-phase acid resistance. This also correlates with the epidemiological data that associated these species with having a lower infective dose compared to other enteric pathogens and confirms the close evolutionary relationship between Escherichia coli and Shigella flexneri amongst the Enterobacteriaceae.

The overall analyses presented herein clearly confirm and adds support to the claim that Shigella species possess acid resistance because they are essentially E. coli [20] in agreement with the taxonomic criteria indicate that Shigella and Escherichia are actually the same genus [21] and have identical virulence determinants that cause clinically indistinguishable disease. [22, 23] The phylogenetic analysis of gadC cluster is in congruent with the high degree of identity between the coding regions of rpoS in $S$. flexneri and E. coli confirms the close taxonomic relationship between the species. [24] This close 


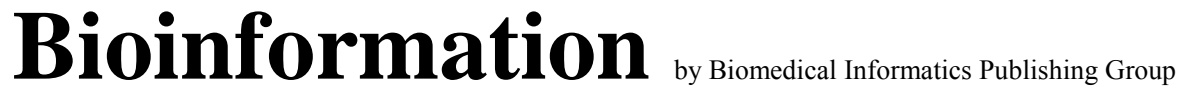

open access

\section{www.bioinformation.net}

Hypothesis

connection (observed from the acid resistance) may lead to the construction of acid resistant vaccine strains which would be effective at low dosages and would not require encapsulation or administration of bicarbonate to ensure passage through the stomach.

\section{Acknowledgment:}

This work was supported by Council of Scientific and Industrial Research (CSIR). SB thanks Mr. R.Aravind and Mr. V.Bhadramurthy, Senior Research Fellows, Pathology Division, Indian Institute of Spices Research for their useful interactions.

\section{References:}

[01] K. S. Gajiwala and S. K. Burley, J Mol Biol., 295: 605 (2000) [PMID: 10623550]

[02] J. W. Foster, et al., Novartis Symp., 221: 55 (1999) [PMID: 10207913]

[03] J. Lin, et al., J Bacteriol., 177: 4097 (1995) [PMID: 7608084]

[04] M. P. Castanie-Cornet, et al., J Bacteriol., 181: 3525 (1999) [PMID: 10348866]

[05] P. D. Cotter, Mol Microbiol., 40: 465 (2001) [PMID: 11309128]

[06] E. F. Gale, et al., Biochem. J., 36: 600 (1942) [PMID: 16747564]

[07] E. A. Auger, et al., Mol. Microbiol., 3: 609 (1989) [PMID: 2527331]

[08] J. L. Slonczewski, et al., J. Bacteriol., 169: 3001 (1987) [PMID: 2954947]
[09] S. R. Waterman and P. L. Small, FEMS Microbiol Lett., 15: 224 (2003) [PMID: 12855178]

[10] J. W. Sanders, et al., Mol Microbiol., 27: 299 (1998) [PMID: 9484886]

[11] Y. Jiang, et al., 54: 149 (2005) [PMID: 16122562]

[12] J. D. Thompson, et al., Nucleic Acids Res., 24: 4876 (1997) [PMID: 9396791]

[13] N. Saitou and M. Nei, Molecular Biology and Evolution, 4: 406 (1987) [PMID: 3447015]

[14] R. D. J. Desper, et al., J Comput Biol., 9: 687 (2002) [PMID: 12487758]

[15] R. R. Sokal and C. D. Michener, Scientific Bulletin, 38: 1409 (1958)

[16] S. Kumar, et al., Brief Bioinform., 5: 150 (2004) [PMID: 15260895]

[17] M. Giangrossi, et al., J Biol Chem., 280: 21498 (2005) [PMID: 15795232]

[18] P. L. C. Small and S. Falkow, Abstr. Gen. Meet. Am. Soc. Microbiol., 74: 38 (1992)

[19] D. K. Smith, et al., J Bacteriol., 174: 5820 (1992) [PMID: 1522060]

[20] J. Gorden, et al., Infection and Immunity, 61: 364 (1993) [PMID: 8418063]

[21] D. J. Brenner, et al., Infect Immun., 6: 308 (1972) [PMID: 4564889]

[22] T. L. Hale, et al., Microbiol. Rev., 55: 206 (1991) [PMID: 1886518]

[23] D. N. Taylor, et al., J. Clin. Microbiol., 26: 1362 (1988) [PMID: 3045152]

[24] P. Small, et al., J Bacteriol., 176: 1729 (1994) [PMID: 8132468]

Edited by $P$. Kangueane

Citation: Manikandan, et al., Bioinformation 2(4): 145-152 (2007)

License statement: This is an open-access article, which permits unrestricted use, distribution, and reproduction in any medium, for non-commercial purposes, provided the original author and source are credited. 
Supplementary material

\begin{tabular}{|c|c|c|c|c|c|c|}
\hline $\begin{array}{l}\text { Sl } \\
\text { No }\end{array}$ & $\begin{array}{l}\text { Primary } \\
\text { accession } \\
\text { number }\end{array}$ & Organism & Sub-species & Strain & $\begin{array}{l}\text { Protein } \\
\text { length } \\
\text { (amino acids) }\end{array}$ & $\begin{array}{l}\text { IMolecular } \\
\text { weight (Da) }\end{array}$ \\
\hline 1 & YP_210202 & Bacteroides fragilis & & $\begin{array}{l}\text { ATCC 25285; } \\
\text { NCTC } 9343\end{array}$ & 532 aa & 57130 \\
\hline 2 & CAJ50406 & Bordetella avium & & $197 \mathrm{~N}$ & 491 aа & 53194 \\
\hline 3 & YP_223596 & Brucella abortus & biovar 1 & $9-941$ & 510 aa & 55080 \\
\hline 4 & NP_541887 & Brucella melitensis & & $16 \mathrm{M}$ & 510 aа & 55150 \\
\hline 5 & NP_829364 & $\begin{array}{l}\text { Chlamydophila } \\
\text { caviae }\end{array}$ & & isolate="GPIC" & 466 aа & 51138 \\
\hline 6 & NP_296865 & $\begin{array}{l}\text { Chlamydia } \\
\text { muridarum Nigg }\end{array}$ & & $\mathrm{MoPn}$ & 466 aa & 50981 \\
\hline 7 & NP_224487 & $\begin{array}{l}\text { Chlamydophila } \\
\text { pneumoniae }\end{array}$ & & CWL029 & 468 aa & 51508 \\
\hline 8 & NP_445023 & $\begin{array}{l}\text { Chlamydophila } \\
\text { pneumoniae }\end{array}$ & & AR39 & 468 aa & 51508 \\
\hline 9 & NP_562976 & $\begin{array}{l}\text { Clostridium } \\
\text { perfringens }\end{array}$ & & 13 & 472 aa & 50926 \\
\hline 10 & AAO91508 & Coxiella burnetii & & RSA 493 & 476 aа & 52577 \\
\hline 11 & NP_820994 & Coxiella burnetii & & RSA 493 & 476 aа & 52446 \\
\hline 12 & ZP_01587708 & Enterobacter sp. & & 638 & 460 aа & 47394 \\
\hline 13 & AĀM46084 & $\begin{array}{l}\text { Enterococcus } \\
\text { faecalis }\end{array}$ & & & 454 aa & 49565 \\
\hline 14 & NP_753817 & Escherichia coli & & CFT073 & 511 aa & 54976 \\
\hline 15 & NP_416009 & Escherichia coli & & $\mathrm{K}-12$ & 511 aa & 54946 \\
\hline 16 & AP_002115 & Escherichia coli & & $\begin{array}{l}\text { K-12, } \\
\text { sub } \\
\text { W3110 }\end{array}$ & 511 aa & 54946 \\
\hline 17 & YP_859796 & Escherichia coli & $\begin{array}{l}\text { Serovar } \\
\text { O1:K1 }\end{array}$ & APEC O1 & 489 aа & 53280 \\
\hline 18 & P58229 & Escherichia coli & & $\mathrm{O} 157: \mathrm{H} 7$ & 511 aa & 55103 \\
\hline 19 & Q8FHG6 & Escherichia coli & & $\mathrm{O} 6$ & 511 aа & 55107 \\
\hline 20 & ABE07184 & Escherichia coli & & UTI89 & 511 aa & 55091 \\
\hline 21 & NP_753817 & Escherichia coli & & CFT073 & 511 aa & 54976 \\
\hline 22 & CAG 45113 & $\begin{array}{l}\text { Francisella } \\
\text { tularensis }\end{array}$ & tularensis & SCHU S4 & 469 aa & 51642 \\
\hline 23 & YP_513914 & $\begin{array}{l}\text { Francisella } \\
\text { tularensis }\end{array}$ & holarctica & LVS & 473 aа & 52696 \\
\hline 24 & YP_666650 & $\begin{array}{l}\text { Francisella } \\
\text { tularensis }\end{array}$ & tularensis & FSC 198 & 469 aа & 51511 \\
\hline 25 & YP_169518 & $\begin{array}{l}\text { Francisella } \\
\text { tularensis }\end{array}$ & tularensis & Schu 4 & 469 aa & 51511 \\
\hline 26 & YP_169957 & $\begin{array}{l}\text { Francisella } \\
\text { tularensis }\end{array}$ & $\begin{array}{l}\text { subsp. } \\
\text { tularensis }\end{array}$ & Schu 4 & 471 aa & 52479 \\
\hline 27 & CAF33981 & Lactococcus lactis & & IPLA 655 & 464 aа & 50641 \\
\hline 28 & O30417 & Lactococcus lactis & Cremoris & & 503 aa & 55369 \\
\hline 29 & AAC46187 & Lactococcus lactis & cremoris & MG1363 & 503 aа & 55369 \\
\hline 30 & NP_562216 & $\begin{array}{l}\text { Clostridium } \\
\text { perfringens }\end{array}$ & & 13 & 485 aa & 52630 \\
\hline 31 & NP_267447 & Lactococcus lactis & lactis & IL1403 & 503 aа & 55434 \\
\hline 32 & YP_095718 & $\begin{array}{l}\text { Legionella } \\
\text { pneumophila }\end{array}$ & pneumophila & Philadelphia 1 & 464 aa & 50647 \\
\hline 33 & YP_095685 & $\begin{array}{l}\text { Legionella } \\
\text { pneumophila }\end{array}$ & pneumophila & Philadelphia 1 & 445 aa & 49056 \\
\hline 34 & YP_094448 & $\begin{array}{l}\text { Legionella } \\
\text { pneumophila }\end{array}$ & pneumophila & Philadelphia 1 & 467 aa & 50332 \\
\hline
\end{tabular}

ISSN 0973-2063 


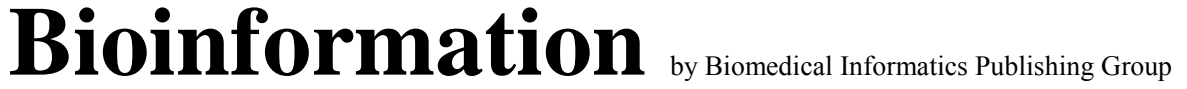

open access

\section{www.bioinformation.net}

Hypothesis

\begin{tabular}{ll}
\hline 35 & AAK17186 \\
36 & AAG22561 \\
37 & ZP_01642072 \\
38 & CAD07591
\end{tabular}

$\begin{array}{ll}39 & \text { YP_403230 } \\ 40 & \text { AAD14843 } \\ 41 & \text { P63236 } \\ 42 & \text { P0AAE7 } \\ 43 & \text { YP_310489 } \\ 44 & \text { CAG41690 } \\ & \\ 45 & \text { NP_720726 } \\ & \\ 46 & \text { NP_078056 } \\ 47 & \text { NP_993425 } \\ & \\ 48 & \text { NP_405843 } \\ & \text { YP_647695 } \\ 49 & \text { YP_070743 } \\ 50 & \end{array}$

Listeria
monocytogenes
Listeria
monocytogenes
Pseudomonas putida
Salmonella enterica

Shigella dysenteriae Shigella flexneri Shigella flexneri

Shigella flexneri Shigella sonnei Staphylococcus aureus

Streptococcus mutans Ureaplasma parvum Yersinia pestis

Yersinia pestis

Yersinia pestis

Yersinia pseudotuberculosis

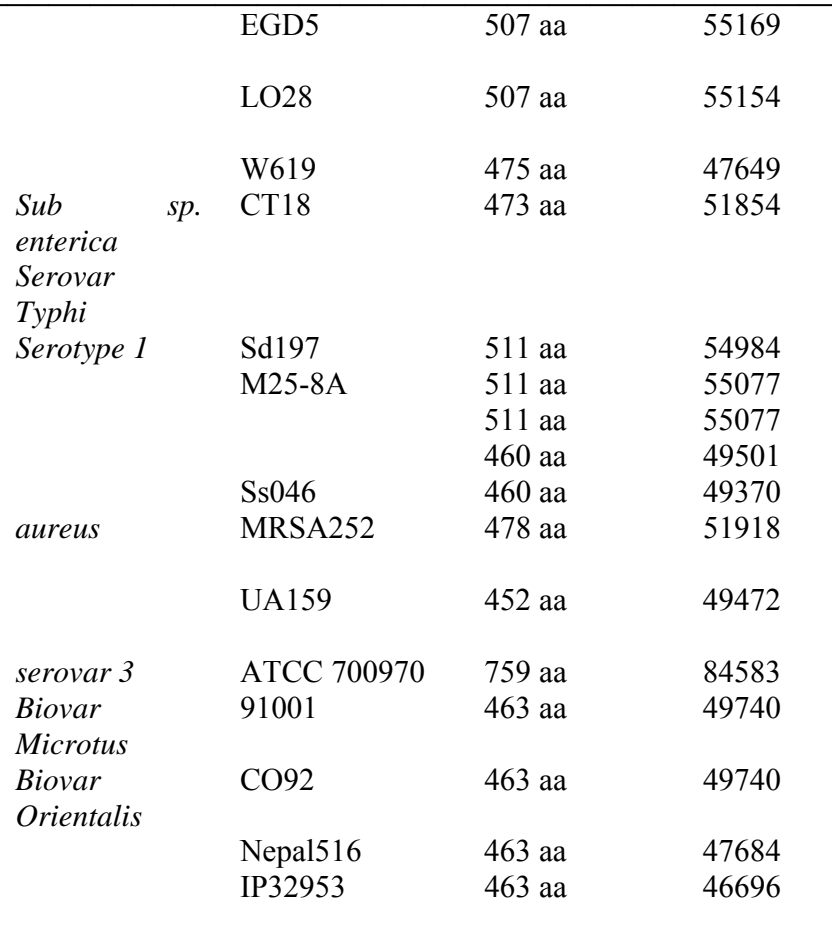

Table 1: Acid sensitivity/resistance antiporter protein sequences retrieved from GenBank. 